\title{
PENGARUH KOMUNIKASI INTERPERSONAL TERHADAP PRODUKTIVITAS KERJA KARYAWAN ROOM DIVISION DEPARTMENT DI HOTEL AXANA PADANG
}

\author{
Ongki Prinanda ${ }^{1}$, Youmil Abrian ${ }^{2}$ \\ Program Studi D4 Manajemen Perhotelan \\ Fakultas Pariwisata dan Perhotelan \\ Universitas Negeri Padang \\ Email : ongkimae@gmail.com
}

\begin{abstract}
Based on this study to determine the effect of interpersonal communication on the work productivity of room division department employees the Axana Hotel Padang. This type of research is causal associative. The sample used is non-probability sampling, which is as many as 35 employees who are in the room division department, through a questionnaire with a Likert scale whose validity and reliability have been tested. The result obtained from this studyare asfollows: (1) Work productivity of room division department employees at the Axana Padang Hotel obtained an average score of $85.7 \%$ categorized as very good. (2) Interpersonal room division department communication at the Axana Padang Hotel obtained an average score of $82.9 \%$ categorized as very good. (3) The results this study indicate that there is no significant influence between variables $X$ and $Y$ with a regression coefficient of 0.265 with sig values. $0.064<0.05$.
\end{abstract}

Keywords: employee work productivity, interpersonal communication

\section{PENDAHULUAN}

Pertumbuhan industri pariwisata Kota Padang mengalami kemajuan yang cukup pesat akhir-akhir ini. Pertumbuhan industri pariwisata yang terjadi tidak terlepas dari aspek-aspek yang mendukungnya, salah satu aspek yang mendukungnya adalah ketersediaan sarana akomodasi atau hotel.Perkembangan dunia perhotelan di Kota Padang, khususnya pasca gempa 2009 menyebabkan adanya persaingan antara hotel-hotel.

Salah satu usaha akomodasi yang ada di Kota Padang adalah Hotel Axana Padang. Hotel Axana Padang merupakan sebuah perusahaan yang bergerak dibidang jasa akomodasi perhotelan dan restoran yang berlokasi di Jalan Bundo Kandung No. 14-16 Padang Barat, Kota Padang, Sumatera Barat.

Hotel Axana memiliki lima lantai dengan bangunan yang dilengkapi berbagai fasilitas standar hotel bintang empat. Hotel ini memiliki jumlah kamar sebanyak 141 kamar yang terbagi menjadi lima tipe kamar. Selain itu Hotel Axana juga memiliki fasilitas lainnya seperti restaurant, lounge, swimming pool, fitness center, spa and massage, billiard dan diskotic. 
Tabel 1. Klasifikasi Kamar di Hotel Axana

\begin{tabular}{|l|l|c|}
\hline No & Jenis Kamar & Jumlah Kamar \\
\hline 1 & Superior Room & 43 kamar \\
\hline 2 & Deluxe Room & 77 kamar \\
\hline 3 & Executive Room & 3 kamar \\
\hline 4 & Family Room & 4 kamar \\
\hline 5 & Junior Suite Room & 6 kamar \\
\hline
\end{tabular}

Sumber: HRD Hotel Axana Padang (2018)

Hotel Axana Padang memiliki sembilan departments dalam mendukung berjalannya operasional dengan baik. Setiap department memiliki karyawan untuk menjalankan tugas di masing- masing department. Karyawan-karyawan tersebut dituntut mampu berkomunikasi dengan baik satu sama lain. Namun, terkadang dalam menjalankan tugasnya sering terjadi miscommunication, yaitu terjadi kesalahpahaman pengertian dalam komunikasi. Hal ini mengakibatkan komunikasi tidak akan berjalan efektif karena pesan yang dikirim tidak dapat diterima dengan baik oleh penerima pesan. Miscommunication ini terjadi baik di dalam satu department maupun antar department. Salah satu bagian hotel yang sering terjadi miscommunication adalah bagian room division.

Rooms Division adalah sebuah bagian pada hotel yang merupakan satuan department dan fungsi yang mempunyai peran penting dan bertanggungjawab untuk pemesanan dan penyediaan kamar serta memberikan pelayanan perawatan, kebersihan dan pemeliharaan kamar serta area umum pada hotel. Bagian yang memiliki tanggung jawab dalam pemesanana dan penyediaan kamar adalah Front Office Department (FO). Sedangkan bagian yang memiliki tanggung jawab terhadap pelayanan jasa perawatan, kebersihan dan pemeliiharaan kamar serta area umum yaitu Housekeeping Department (HK). Karyawan yang bekerja pada bagian room division selalu diharapkan mampu meningkatkan produktivitas dalam bekerja.

Produktivitas kerja karyawan di Hotel Axana Padang, khususnya di room division memiliki masalah. Masalah tersebut diantaranya adalah lambatnya kerja room boy dalam proses make up room. Pada Standart Operational Procedure (SOP) make up room di Hotel Axana Padang, room boy hanya diberi waktu selama 20 menit untuk mempersiapkan satu kamar. Akan tetapi, room boy sering mencatat waktu lebih dari 20 menit untuk mempersiapkan kamar. Hal ini mengakibatkan tamu yang komplain kepada reception karena terlalu lama menunggu kamar yang telah mereka booking untuk bisa ditempati. Selain itu, lambatnya kerja room boy dalam proses 
make up room juga dipengaruhi adanya faktor late check out.

Masalah produktivitas lainnya adalah tentang produktivitas kerja front desk. Dalam hal ini, front desk memakan waktu yang terlalu lama untuk melakukan pelayanan proses check in ataupun check out kepada tamu. Peristiwa ini cukup sering terjadi sehingga membuat daftar antrean tamu menjadi panjang. Selain lamanya proses check in dan check out, front desk juga memiliki masalah produktivitas lainnya. Masalah tersebut yaitu lamanya waktu yang dibutuhkan untuk membuat report pekerjaan, sehingga membuat jam kerja bertambah. Kejadian ini terjadi dikarenakan front desk yang suka menunda-nunda untuk membuat report.

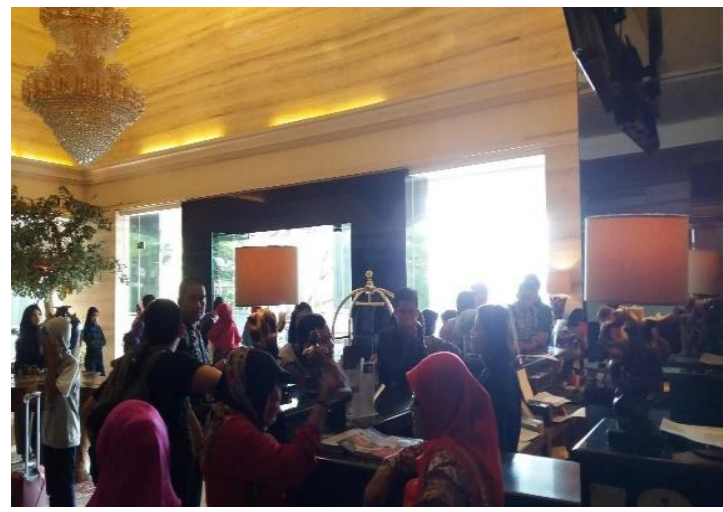

Gambar 1. Antrean tamu check in dan check out di Hotel Axana Padang Sumber : Dokumentasi Penelitian, 2018

Produktivitas kerja karyawan dipengaruhi oleh beberapa faktor. Sebagaimana yang diungkapkan Sutrisno (2009), "Terdapat tiga faktor yang mempengaruhi produktivitas kerja karyawan yaitu : 1) Pelatihan, berkenaan dengan kemampuan dalam mengerjakan sesuatu dengan tepat dan benar, 2) Mental karyawan, mencakup hubungan komunikasi antar sesama karyawan, 3) Hubungan atasan dan bawahan, yaitu pandangan antara atasan terhadap bawahan maupun sebaliknya".

Saat melaksanakan Pengalaman Lapangan Industri (PLI) di Hotel Axana Padang periode Agustus - Desember 2017, penulis melihat beberapa permasalahan yang terjadi antara front office department dan housekeeping department. Permasalahan pertama yang penulis amati adalah sering terjadinya perbedaan report mini bar pada kedua department tersebut. Selain itu, saat front desk meminta room boy untuk terlebih dahulu membersihkan kamar yang sudah di request sebelumnya, karena tamu reservasi yang akan menempati kamar tersebut sudah menunggu. Akan tetapi room boy sering kali mengabaikan pesan tersebut, sehingga mengakibatkan tamu tersebut menjadi complaint dikarenakan lamanya menunggu kamar tersebut siap digunakan.

Permasalahan selanjutnya, yaitu pada saat tamu tidak merasa nyaman pada kamar yang ditempati, dan ingin melakukan perpindahan kamar. Pada saat front desk telah memproses permintaan tamu untuk pindah kamar, terkadang front desk tidak memberi konfirmasi pada housekeeping bahwa terjadi perpindahan kamar. Hal ini tentu membuat terjadinya perbedaan informasi antara kedua department tersebut

\section{METODE PENELITIAN}

Penelitian ini menggunakan metode deskriptif kuantitatif dengan 
pendekatan asosiatif kausal. Sampel yang digunakan non probability sampling yaitu sebanyak 35 orang karyawan yang berada pada departemen room division, dengan kuesioner yang memakai skala likert dengan validitas dan reliabilitasnya yang telah teruji. Teknik pengolahan data dilakukan dengan cara mentabulasi data, selanjutnya menjelaskan deskripsi data, lalu menghitung berdasarkan kategori skor. Uji persaratan analiisis dilakukan lewat menghitung uji normalitass serta uji homogenitas. Teknik analisis data memakai uji regresi linear sederhana yang bertujuan untuk menentukan pengaruh variabel $\mathrm{X}$ terhadap variabel Y. Kriteria pengambilan keputusan adalah :
1. Jika nilai signifikansi $<0,05$, maka Ha diterima dan Ho ditolak

2. Jika nilai signifikansi $>0,05$, maka Ho diterima dan Ho ditolak

\section{HASIL DAN PEMBAHASAN}

\section{Komunikasi Interpersonal}

Data komunikasi interpersonal didapat lewat penyataan yang berjumlah 22 point. Setelah itu, angket diberikan pada 35 karyawan agar segera dijawab. Untuk distribusi frekuensi komunikasi interpersonal dapat dilihat ditabel dibawah ini:

Tabel 2. Distribusi Frekuensi Komunikasi Interpersonal

\begin{tabular}{|c|c|c|c|}
\hline Kategori & Skor & Frekuensi & \% \\
\hline Sangat Baik & $\geq 87,9$ & $\mathbf{3 0}$ & $\mathbf{8 5 , 7}$ \\
\hline Baik & $73,3-<87,9$ & 5 & 14,3 \\
\hline Cukup & $58,7-<73,3$ & 0 & 0 \\
\hline Buruk & $44,1-<58,7$ & 0 & 0 \\
\hline Sangat Buruk & $<44,1$ & 0 & 0 \\
\hline Total & & $\mathbf{3 5}$ & $\mathbf{1 0 0}$ \\
\hline
\end{tabular}

Sumber: Hasil Pengolahan Data, 2018

Berdasarkan tabel di atas, distribusi data variabel komunikasi interpersonal terdapat $85,7 \%$ responden yang termasuk dalam kategori sangat baik, $\quad 14,3 \%$ respnden termasuk dalam kategori baik, $\quad 0.0 \% \quad$ responden termasuk kategori cukup, $0.0 \%$ responden termasuk dalam kategori buruk, $0.0 \%$ responden termasuk pada kategori sangat buruk.
2. Produktivitas Kerja Karyawan

Data produktivitas kerja karyawan didapat lewat penyataan yang berjumlah 14 point. Selanjutnya, angket disebarkan kepada 35 responden untuk dijawab. Untuk distribusi frekuensi produktivitas kerja karyawan dapat dilihat ditabel dibawah ini: 
Tabel 3. Distribusi Frekuensi Produktivitas Kerja Karyawan

\begin{tabular}{|c|c|c|c|}
\hline Kategori & Kelas interval & Frekuensi & \% \\
\hline Sangat Baik & $\geq 55,95$ & $\mathbf{3 0}$ & $\mathbf{8 5 , 7}$ \\
\hline Baik & $46,65-<55,95$ & 4 & 11,4 \\
\hline Cukup & $37,35-<46,65$ & 1 & 2,9 \\
\hline Buruk & $28,05-<37,35$ & 0 & 0 \\
\hline Sangat Buruk & $<28,05$ & 0 & 0 \\
\hline Total & & $\mathbf{3 5}$ & $\mathbf{1 0 0}$ \\
\hline
\end{tabular}

Sumber: Hasil Pengolahan Data, 2018

Berdasarkan penjabaran mengenai distribusi data variiabel produktivitas kerja karyawan, $85,7 \%$ koresponden yang tergabung pada kategori sangat baik, 11,4\% dalam kategori baik, 2,9\% tergabung pada kategori cukup,
$0,0 \%$ katagori buruk dan $0,0 \%$ ke dalam katagori sangat buruk.

\section{Analisis Data}

\section{a. Uji Normalitas}

Hasil uji normalitas ini dapat dilihat pada tabel di bawah ini :

Tabel 4. Hasil Uji Normalitas

One-Sample Kolmogorov-Smirnov Test

\begin{tabular}{|c|c|c|c|}
\hline & & $\begin{array}{l}\text { Komunikas } \\
\mathrm{i} \\
\text { Interperson } \\
\text { al }\end{array}$ & $\begin{array}{l}\text { Produktivit } \\
\text { as Kerja } \\
\text { Karyawan }\end{array}$ \\
\hline \multicolumn{2}{|l|}{$\mathrm{N}$} & 35 & 35 \\
\hline \multirow[t]{2}{*}{ Normal Parameters ${ }^{a,, b}$} & Mean & 95.03 & 59.00 \\
\hline & Std. Deviation & 5.480 & 4.602 \\
\hline \multicolumn{2}{|c|}{ Most Extreme Differences Absolute } & .109 & .214 \\
\hline & Positive & .100 & .081 \\
\hline & Negative & -.109 & -.214 \\
\hline \multicolumn{2}{|l|}{ Kolmogorov-Smirnov Z } & .642 & 1.266 \\
\hline \multicolumn{2}{|l|}{ Asymp. Sig. (2-tailed) } & .804 & .081 \\
\hline
\end{tabular}

a. Test distribution is Normal.

b. Calculated from data.

Sumber: Hasil Pengolahan Data, 2018 
Nilai signifikansi komunikasi interpersonal dan produktivitas kerja karyaawan secara berurutan yaitu 0,804 dan 0,81 . Dengan nilai signifikansi yang lebih besar darii 0,05 , sehinnga dapat disimpulkan kedua variabel berdistribuusi normaI

\section{b. Uji Homogeniitas}

Hasil uji homogenitas penelitian ini akan ditampilkan pada tabel berikut.

Tabel 5. Hasil Uji Homogenitas

Test of Homogeneity of Variances

Produktivitas_Kerja_Karyawan

\begin{tabular}{|c|c|c|c|}
\hline $\begin{array}{l}\text { Leven } \\
\text { e } \\
\text { Statisti } \\
\text { c }\end{array}$ & df1 & df2 & Sig. \\
\hline $\begin{array}{l}1.87 \\
8\end{array}$ & G & 17 & $\begin{array}{l}.12 \\
6\end{array}$ \\
\hline
\end{tabular}

Sumber: Hasil Pengolahan Data, 2018

Nilai signifikansi yaitu 0,126 degan taraf siignifikansi $>0,05$. Hal tersebut berarti nilai signifikanasi data lebih besar dari tarap signifikani. Dengan demikian maka data berasal dari populasi dengan varian yang sama dan bersifat homogen.

\section{c. Uji Linearitas}

Uji linearitas pada penelitian ini dapat dilihat pada tabel berikut.

Tabel 6. Hasil Uji Linieritas

ANOVA Table

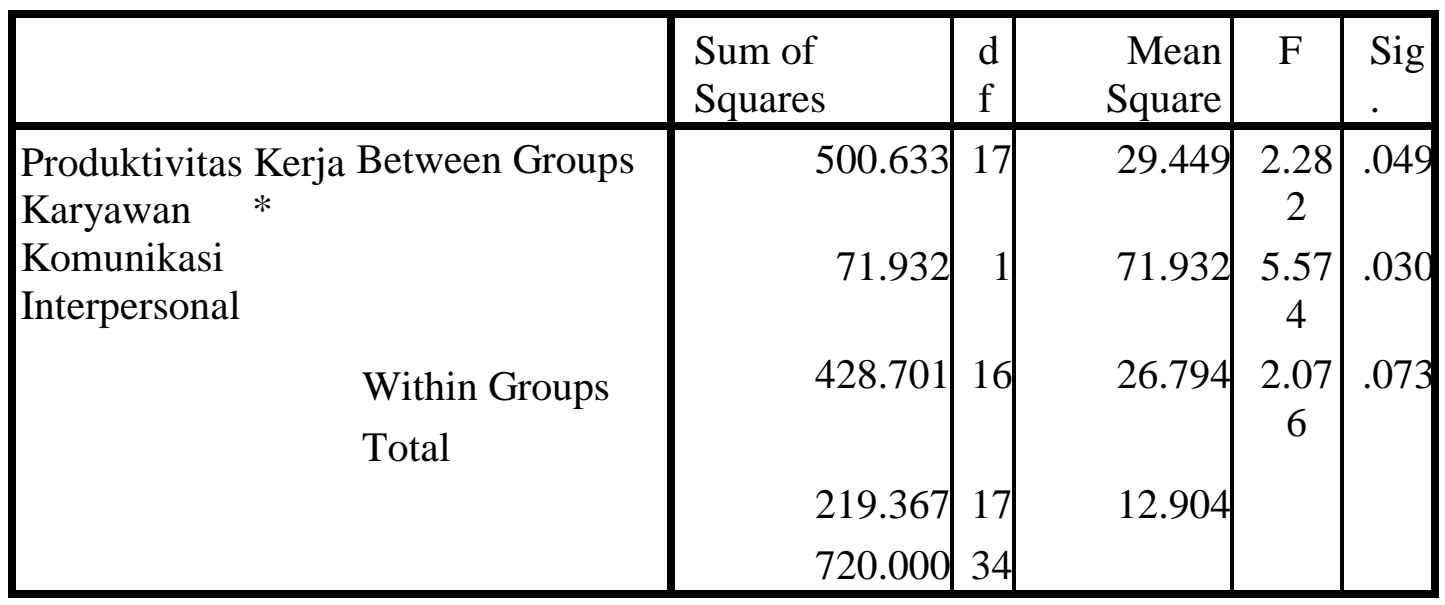

Sumber: Hasil Pengolahan Data, 2018 
Berdasarkan hasil analisis uji linearitas pada tabel di atas, diperoleh nilai Sig adalah 0,073 dengan taraf signifikansi > 0,05. Hal ini berarti terdapat hubungan linear secara signifikan antara variabel komunikasi interpersonal (X) dan produktivitas kerja karyawan (Y).

\section{Pengujian Hipotesis}

Uji regresi linear sederhana dalam pengujian hipotesis program SPSS 17.00 dengan hasil seperti tabel dibawah ini :

\begin{tabular}{|c|c|c|c|c|c|c|}
\hline \multicolumn{7}{|c|}{ ANOVA $^{b}$} \\
\hline & Model & Sum of Squares & Df & Mean Square & $\mathrm{F}$ & Sig. \\
\hline 1 & Regression & 71.932 & 1 & 71.932 & 3.663 & $.064^{\mathrm{a}}$ \\
\hline & Residual & 648.068 & 33 & 19.638 & & \\
\hline & Total & 720.000 & 34 & & & \\
\hline
\end{tabular}

a. Predictors: (Constant), Komunikasi_Interpersonal

b. Dependent Variable: Produktivitas_Kerja_Karyawan

Table 7. Hasil Uji Regresi Linear Sederhana

Sumber: Hasil Pengolahan Data, 2018

Hasil uji regresi linier diatas menunjukkan nilai $\mathrm{F}$ 3,663 dengan signifikansi 0,064. Hal tersebut berarti variabel komunikasi

\begin{abstract}
interpersonal tidak berpengaruh terhadap variabel

produktivitas kerja karyawan, maka

Ha ditolak dan H0 diterima
\end{abstract}

. Tabel 8. Koefisien Regresi Variabel X Terhadap Y

Coefficients $^{\mathrm{a}}$

\begin{tabular}{|c|c|c|c|c|c|}
\hline \multirow[b]{2}{*}{ Model } & \multicolumn{2}{|c|}{$\begin{array}{c}\text { Unstandardized } \\
\text { Coefficients }\end{array}$} & \multirow{2}{*}{$\begin{array}{c}\begin{array}{c}\text { Standardized } \\
\text { Coefficients }\end{array} \\
\text { Beta }\end{array}$} & \multirow[b]{2}{*}{$\mathrm{t}$} & \multirow[b]{2}{*}{ Sig. } \\
\hline & B & Std. Error & & & \\
\hline $1 \quad$ (Constant) & 33.776 & 13.201 & & 2.559 & .015 \\
\hline Komunikasi_Interpersonal & .265 & .139 & .316 & 1.914 & .064 \\
\hline
\end{tabular}

a. Dependent Variable: Produktivitas_Kerja_Karyawan

Sumber: Hasil Pengolahan Data, 2018 
Berikutnya yaitu menghitung seberapa besar koofisien regreasi antar variabel komunikasi interpersonal $(\mathrm{X})$ terhadap produktivitas kerja karyawan (Y), dapat dilihat pada persamaan berikut.

\section{$Y=33,776+0,265 X$}

Setelah melihat jabaran di atas, maka diperoleh koefisien regresi sebesar 0,265 dengan nilai sig. 0,064 .

\section{Pembahasan}

Setelah melakukan penelitian di Hotel Axana Padang, maka dapat diuraikan pembahasan tentang komunikasi interpersonal dengan produktivitas kerja karyawan serta pengaruh antara kedua variabel tersebut. Dari analisa dapat diketahui bahwa variabel independent (komunikasi interpersonal) tidak berpengaruh terhadap variabel dependent (produktivitas kerja karyawan). Penjelasannya adalah sebagai berikut:

\section{a. Komunikasi Interpersonal (X)}

$$
\text { Berdasarkan hasil }
$$
penilaian dari 35 sampel, variabel komunikasi interpersonal memperoleh sebanyak $85,7 \%$ responden yang termasuk dalam kategori sangat baik dan $14,3 \%$ responden termasuk dalam kategori baik. Setelah melihat hasil penilaian tersebut, maka dapat diartikan komunikasi interpersonal karyawan room division di The Axana Hotel Kota Padang masuk dalam kategori sangat baik.

Menurut Josep A. DeeVito (2013), "Komunikasi interpersonal adalah interaksi verbal dan non verbal antara dua (atau kadang-kadang lebih dari dua) orang yang saling tergantung satu sama lain". Berdasarkan penjelasan tersebut, dapat diartikan bahwa semua pelaku komunikasi interpersonal memiliki peran yang sama-sama penting dalam berinteraksi demi tercapainya komunikasi interpersonal yang baik.

Komunikasi

interpersonal sejatinya memiliki fungsi untuk meningkatkan hubungan kemanusiaan sehingga bisa mempermudah seseorang dalam menjalani kehidupan sehari-hari. Apabila komunikasi interpersonal tersebut telah terjalin dengan baik, maka akan dapat menghindari atau bahkan mengatasi konflik yang terjadi.

\section{b. Produktivitas Kerja Karyawaan (Y)}

Setelah menghitung penilaiian dari 35 koresponden variabel produktivitas kerja kryawan, memperoleh sebanyak $85,7 \%$ responden yang termasuk dalam kategori sangat baik, $11,4 \%$ responden tergabung 
dalam kategori baik dan 2,9\% responden termasuk dalam skor cukup. Setelah melihat hasil penilaian tersebut, maka dapat diartikan produktivitas kerja karyawan room division di The Axana Hotel Kota Padang masuk dalam kategori sangat baik.

Menurut Sunyoto

Danang (2012), "Produktivitas kerja adalah ukuran yang menunjukkan pertimbangan antara input dan output yang dikeluarkan perusahaan serta peran tenaga kerja yang dimiliki persatuan waktu". Jika produktivitas kerja karyawan tinggi, maka menghasilkan jumlah yang lebih besar dibanding dengan jumlah masukan.

c. Pengaruh

Interpersonal

Produktivitas

Karyawan di Hotel Axana Padang

Untuk dapat melihat pengaruh antara komunikasi interpersonal terhadap produktivitas kerja karyawan di Hotel Axana Padang, maka menggunakan hasil uji hipotesis. Analisis dilakukan melalui program SPSS 17.00 dan didapat hasil uji regresi linear sederhana dengan nilai $\mathrm{F} 3,663$ dengan taraf sig. $0,064<0,05$ dan nilai $\mathrm{T}$ 1,914 dengan taraf sig. $0,064<0,05$, dapat disimpulkan bahwa komunikasi interpersonal tidak berpengaruh terhadap keputusan pembelian, maka Ha ditolak dan $\mathrm{H} 0$ diterima. Selanjutnya koeffisien reggresi sebesar 0,265 pada siig. $0,064<0,05$.

Setermeister dalam

Winardy (2008: 10) berpendapat, "Salah satu cara dalam meningkatkan produktivitas kerja yaitu dengan cara memperbaiki komunikasi interpersonal menjadi lebih efektif'. Komunikasi interpersonal yang terjalin dengan baik akan memberikan iklim serta mental kerja yang baik juga bagi karyawan, sehingga menciptakan etos kerja yang tinggi. Dengan tingginya etos kerja karyawan, maka akan berdampak pada meningkatnya produktivitas kerja karyawan.

\section{KESIMPULAN DAN SARAN}

\section{KesimpuIan}

a. Hasil tentang komunikasi interpersonal di Hotel Axana Padang menunjukkan kategori sangat baik dengan nilai persentase $82,9 \%$.

b. Hasil penilaian tentang produktivitas kerjaa karyawaan di Hotel Axana Padang memperlihatkan kategori sangat baik dengan nilai persentase $85,7 \%$.

c. Tidak terdapat pengaruh yang signifikan antara komunikasi interpersonal terhadap produktivitas kerja 
karyawan. Berdasarkan analisis uji regresi linier sederhana didapati $\mathrm{F}$ hitung 3,663 dengan sig. 0,064< 0,05 . Selanjutnya, diperoleh persamaan dengan koefisien regresi sebesar 0,265 dengan nilai sig. $0,064<0,05$.

\section{Saran}

a. Bagi pihak hotel disarankan agar dapat mempertahankan komunikasi interpersonal antar karyawan khususnya departemen room division yang dimana menurut penelitian ini hasilnya sangat baik. Selain itu pihak hotel diharapkan agar melihat potensi lain yang dapat mempengaruhi produktivitas kerja karyawan di room division

b. Bagi Jurusan Pariwisata disarankan untuk dapat menambah atau melengkapi buku referensi di perpustakaan yang berkaitan dengan komunikasi.

c. Bagi peneliti lain disarankan mencari pengaruh lain selain komunikasi interpersonal yang bisa memberi pengaruh pada produktivitas kerja karyawan, diantaranya disiplin kerja, keterampilan, teknologi dan faktor lainnya.

\section{DAFTAR PUSTAKA}

Danang, Sunyoto. 2012. Manajemen Sumber Daya Manusia. Jakarta: PT Buku Seru.

Halimah, Siti. 2014. "Hubungan Disiplin Kerja Dengan Produktivitas Kerja Karyawan

$$
\text { Pada PT Mitra Saruta }
$$

Indonesia di Gresik"

$$
\begin{aligned}
& \text { http://digilib.uinsby.ac.id/456/3/ } \\
& \text { 02 Mab\%202.pdf (diakses tanggal }
\end{aligned}
$$

Hidayat, Rahmat dan Uliya Hasanah. 2016 "Hubungan Komunikasi Terhadap Produktivitas Kerja Karyawan"

https://jurnal.polibatam.ac.id/ind ex.php/JAEMB/article/downloa d/79/71/ (diakses tanggal 26 Maret 2018)

Sutrisno, Edy. 2009. Manajemen Sumber Daya Manusia. Edisi Pertama. Jakarta: Pernada Media Group.

Thoha, Miftah. 2008. Perilaku Organisasi. Konsep Dasar dan Aplikasinya. Jakarta: Raja Grafindo Persada. 